\title{
METACONTEXTO INTERCULTURAL E DIÁRIO DOCENTE
}

Marcos Gustavo Richter

mrichter@cal.ufsm.br

Dioni Maria dos Santos Paz

dionipaz@smail.ufsm.br

dioni-paz@uergs.edu.br

\section{RESUMO}

O objetivo deste artigo é tecer algumas considerações sobre práticas sociais docentes relatadas em um diário concebido como gênero textual ligado à formação inicial, na vertente teórica de Bakhtin (1992) e Bronckart (1999). Para tanto, serão consideradas as crenças e a cultura de ensinar de uma acadêmica-professora em um curso de português para hispanofalantes. Essa acadêmica, conforme podemos indiciar a partir de seu texto, procedeu a uma horizontalização superadora das hierarquias e diferenças interculturais, elicitando a emergência de uma relação do aluno com o contexto pessoal até antes apagado e propiciando, dessa forma, a construção de um metacontexto intercultural de prática de leitura.

\section{INTRODUÇÃO}

A formação de professores tem ocupado grande parte das discussões sobre a cultura de ensinar e a cultura de aprender (Reynaldi, 1999). Formar mão-de-obra qualificada no ensino de línguas, ou seja, gerir iniciativas de formação inicial e continuada de docentes reflexivo-críticos é um trabalho complexo, que requer uma visão holística do profissional e de seu contexto. Isto requer uma arquitetura de procedimentos baseada não só na integração entre reflexão e ação numa espiral de complexidade crescente - pesquisa-ação educacional na tradição de Carr e Kemmis -, mas também na premissa de que papéis e práticas sociais somente podem ser equacionados e problematizados em termos de relações emergentes entre estruturas. (Bateson, 1979; Morin,1996).

Ora, esta abordagem implica uma teoria das ações de linguagem baseada nos princípios do sócio-interacionismo e numa concepção de língua como uma realidade concreta, processual e dialética, que manifesta no plano lingüístico e semiótico condutas humanas, encaradas como um amálgama indissociado de crenças, ações e sentimentos situados. Essas condutas, resultantes da socialização dos indivíduos e da internalização de culturas, são mediadas, no sentido vygotskiano do termo, pela rede discursiva coalescida em "ilhotas" de regularidades textuais históricas e mutáveis 
(correspondentes a práticas sociais específicas) que são os gêneros - um dos quais, que nos interessa particularmente, é o diário docente.

Este artigo, recortando suas indagações deste fundo, objetiva analisar e repensar as práticas discursivas docentes em um diário visto como discurso e prática social, segundo os preceitos de Bakhtin (1992) e Bronckart (1999). Para tanto, serão observadas as crenças e a cultura de ensinar de uma acadêmica-professora que procedeu a uma horizontalização de superação das hierarquias e diferenças interculturais, elicitando a emergência de uma relação do aluno com o contexto pessoal até antes apagado, propiciando a construção de um metacontexto intercultural de leitura.

Dentro da abordagem da pesquisa-ação (Carr e Kemmis,1986 e Serrano,1990), este trabalho fundamenta-se na perspectiva da teoria do sócio-letramento de Gee (1999), na perspectiva intercultural da educação de Fleury (1998), no modelo cultural da mente de D’Andrade (1987) e na teoria sócio-histórica da formação de conceitos de Vygotsky (1993). Temos procurado investigar como as representações docentes manifestam-se na forma de traços de gênero no processo cognitivo de acadêmicos inseridos na prática social docente. Através do diário de uma aluna — portanto em um estudo de caso - pode-se realizar um acompanhamento linear da maturação conceitual da acadêmica, ou seja, proceder a focalizações sucessivas do tratamento dado à problemática que ocupa o centro de suas reflexões, sem perder as referências do contexto didático. Esse procedimento situado e relacional permite flagrar aproximações e distanciamentos entre os níveis descritivo e valorativo do processo de investigação e reflexão do professor. (Porlán e Martín, 1997)

\section{CONSIDERAÇÕES SOBRE GÊNEROS DE TEXTO}

Se entendermos os gêneros textuais como

produtos da atividade de linguagem em funcionamento permanente nas formações sociais em função de seus objetivos, interesses e questões específicas, essas formações elaboram diferentes espécies de textos, que apresentam características relativamente estáveis (justificando-se que sejam chamadas de gêneros de texto) e que ficam disponíveis no intertexto como modelos indexados, para os contemporâneos e para as gerações posteriores. (Bronckart,1999:137) 
inferimos que os textos são produtos culturais e, em função disso, as produções textuais são representações da articulação de situações de ação com motivos e intenções socialmente construídos, e essas representações, por sua vez, manifestam regularidades configuradas nos gêneros de textos vigentes nessa cultura. Em suma, todo texto pertence a um gênero, em função da situação de ação de que se origina e de que, dialeticamente, é uma resposta.

Segundo Marcuschi (2002:43), a conceituação de gênero é de natureza sóciocomunicativa, baseada em parâmetros pragmáticos, visto que sua sedimentação se dá através de práticas sociais desenvolvidas e testadas, para atingir propósitos comunicativos. Esses propósitos contemplam a concepção de que

\begin{abstract}
A utilização da língua efetua-se em forma de enunciados (orais e escritos), concretos e únicos, que emanam dos integrantes duma ou outra esfera da atividade humana. $O$ enunciado reflete as condições específicas $e$ as finalidades de cada uma destas esferas, não só pelo conteúdo (temático) e por seu estilo verbal, ou seja, pela seleção operada nos recursos da língua recursos lexicais, fraseológicos e gramaticais - mas também, e sobretudo, por sua construção composicional. (Bakhtin,1992:279)
\end{abstract}

Faz-se necessário que os diversos contextos sociais sirvam-se de múltiplos gêneros textuais para responder aos anseios de determinados grupos sociais. Para Bronckart (1999), a espécie humana caracteriza-se pela diversidade e pela complexidade de suas formas de organização e de suas formas de atividades. Essas peculiaridades fazem com que se considere as ações humanas em suas dimensões sociais e discursivas. Decorrente dessa colocação, justifica-se o estatuto da linguagem humana como uma esfera de produções interativas associadas às atividades sociais resultantes do meio em que as atividades se desenvolvem. Nessa abordagem, assim como a atividade social pode ser enfocada sob o ângulo psicológico da ação, a atividade lingüística também pode ser vista como ação de linguagem. Essa manifestação, condicionada a um emissor concreto, se materializa através de gêneros textuais. Vygotsky (1993) acrescenta a esta perspectiva o papel da linguagem como mediadora da cooperação social, junto com os instrumentos de produção desenvolvidos pelas comunidades.

Ainda segundo Bronckart (1999:43),

contribuindo para a atividade de linguagem, cada ser humano, portanto, participa das avaliações sociais e, nesse quadro, aplica os critérios coletivos 
de avaliação e "julga" a pertinência do agir dos outros em relação aos mundos representados.

O caráter inerentemente valorativo da atividade de linguagem ressalta a importância pedagógica de trabalhar sob a perspectiva da complexidade (Morin,1996; Fleury,1998), pois os grupos humanos, caracterizando-se pela diversidade e pela complexidade de suas formas de organização e de atividade social, inevitavelmente se vêem diante do desafio de confrontar e transcender produtivamente diferenças entre pessoas em relação e entre contextos em relação, até chegar à construção de metacontextos nos quais a relação de disjunção cultural (ou/ou) é superada como relação de síntese (e/e). Ou seja, para Fleury, reconhecer uma relação humana como complexa implica relativizar os contextos na interação pedagógica - atenuando (horizontalizando) a hierarquização das diferenças - para então buscar o entrelaçamento entre as perspectivas de sujeitos e contextos diferentes. Nessa abordagem, os conceitos surgem de áreas diferentes, de grupos diferentes e de situações diferentes e se iluminam reciprocamente. Esse é o princípio das relações interculturais, nas quais os conceitos se realizam na articulação de diferentes grupos sociais, a partir do respeito às diferenças e aos valores culturais.

\section{O GÊNERO DIÁRIO DOCENTE E A PRÁTICA SOCIAL REFLEXIVA}

Um enfoque realmente superador do ensino tradicional deve favorecer uma racionalidade da prática educativa, convertendo-a em uma prática fundamentada e rigorosa, e incorporando conhecimentos procedentes de diversos campos do saber. Por sua vez, o professor é habitualmente visto como um prático que toma inúmeras decisões intuitivas sobre seu comportamento concreto. Esse comportamento, porém, é influenciado por um sistema de crenças e opiniões enraizado e pode não se adequar mecanicamente, pois é o resultado da influência de diversas variáveis (emocionais, cognitivas e atitudinais) que interagem com o contexto. Portanto, há um processo complexo que escapa do controle consciente do professor e, por isso, precisa emergir gradativamente para ser retrabalhado em condições intersubjetivas e metódicas — os procedimentos de formação inicial e continuada.

Porlán e Martín (1997:17) propõem 
um sujeito que, levando em consideração as características e necessidades do contexto de onde tem lugar sua atividade e as orientações, prescrições e fundamentações teóricas que considera significativas, planilha, desenha e avalia sua intervenção.

Este perfil profissional tem fundamentação teórica na investigação-ação educacional (Carr e Kemmis, 1986; Serrano,1990). Por conseguinte, a partir desse ponto de vista, o professor é aquele que diagnostica os problemas, formula hipóteses de trabalho, escolhe seus materiais e desenha as atividades. Portanto, o professor é o próprio investigador de sua aula.

Por outro lado, a investigação e o tratamento pelos professores de seus problemas práticos contribuem para explicitar crenças e teorias implícitas em suas ações, bem como ajudam a planejar hipóteses de intervenção para resolver os problemas por outras perspectivas.

\footnotetext{
Um recurso metodológico nuclear para todo este processo é o diário. Sua utilização periódica permite refletir o ponto de vista do autor sobre os processos mais significativos da dinâmica em que está imerso. É um guia para a reflexão sobre sua prática, favorecendo uma tomada de consciência sobre seu processo de evolução e sobre seus modelos de referência. (Porlán e Martín,1997: 19-20)
}

A proposta deste trabalho consiste em explorar alguns aspectos de um diário professoral, enfocado como uma forma social de reflexão sobre as escolhas, crenças, valores e atitudes docentes, forma essa reconhecida por sua estabilidade lingüística e manifestada em contextos comunicativos específicos - o que leva este objeto de linguagem a uma reconhecida convencionalidade no formato e no uso: um legítimo gênero e instrumento. Procuraremos mostrar como o diário permite verbalizar e abstrair reflexivamente momentos de superação de diferenças de ordem cultural (professor $x$ aluno) em contextos de ensino de português para estrangeiros.

\section{PROCEDIMENTOS METODOLÓGICOS}

Este estudo procede a uma análise dos processos cognitivos de uma acadêmicadocente, encontrados num fragmento de seu diário, levantando os traços relevantes da linguagem através do paradigma indiciário (Guinzburg, 1998). Para tanto, a metodologia será delineada da seguinte forma: 
a) análise das crenças que se expressam através das ações, nos mundos sociais e nas ideologias que, ao mesmo tempo, regulam a distribuição de qualquer 'bem' social que as pessoas percebam como relevante, dentro da perspectiva do sócioletramento (Gee,1999).

b) análise dos parâmetros cognitivos de um modelo cultural da mente (D'Andrade,1987), tentando explicar as crenças através da percepção de eventos externos e dos sentimentos pessoais.

\section{CONTEXTO DE PRODUÇÃO}

Segundo Bronckart (1999:93),

o contexto de produção pode ser definido como o conjunto dos parâmetros que podem exercer uma influência sobre a forma como o texto é organizado. Esses fatores estão reagrupados em dois conjuntos: o primeiro refere-se ao mundo físico e o segundo, ao mundo social e ao subjetivo.

Quanto ao primeiro fator, todo texto resulta de um comportamento verbal concreto, desenvolvido por um agente situado no espaço e no tempo; portanto, todo texto resulta de um ato realizado em um contexto físico, que pode ser definido por quatro parâmetros: o lugar da produção, o momento da produção, o emissor, e o receptor.

Para contextualizar, os diários das acadêmicas são produzidos, individualmente, após terem ministrado cada aula de português para estrangeiros, na sala onde se realizam as aulas, no laboratório PLE (Português-Língua Estrangeira), localizado no Centro de Educação da Universidade Federal de Santa Maria-RS, ou em casa. Estão organizados por ordem de elaboração cronológica e colocados em pastas, para serem feitas leituras horizontais da evolução dos conceitos de ensino de leitura adquiridos pelas acadêmicas durante a trajetória do curso.

No contexto social e subjetivo, a produção de um texto inscreve-se no quadro das atividades de uma formação social e, mais precisamente, no quadro de uma forma de interação comunicativa que implica o mundo social (normas, valores, regras, etc.) e o mundo subjetivo (imagem que o agente dá de si ao agir). Esse contexto sóciosubjetivo é reconhecido também por quatro parâmetros: o lugar social, ou seja, em 
que modo de interação o texto é produzido (família, escola, mídia, etc.); a posição social do emissor, ou seja, qual o papel social que o emissor desempenha na interação (de professor, de pai, de cliente, etc.); a posição social do receptor, ou seja, qual o papel social atribuído ao receptor do texto (de aluno, de criança, de colega, etc.); o objetivo da interação, ou seja, qual o efeito que o texto pode produzir nos destinatários.

Ao escrever os diários, as autoras estão inseridas em uma posição social que lhes dá o estatuto de enunciador, isto é, elas agora desempenham o papel de escritor (de uma narrativa pessoal descritiva), mantendo, assim, uma interação com o receptor (a equipe de docentes-orientadores), que, por sua vez, recebe o estatuto de destinatário com o papel de leitor dos diários. Portanto, dentro dos fundamentos da teoria do interacionismo sócio-discursivo vygotskyano tem-se, como ponto de partida, o ato de comunicação com todos os seus pressupostos psicológicos e sociológicos inseridos numa específica situação comunicativa.

Partindo-se dessa constatação, pode-se dizer que os diários são escritos por sujeitos inseridos em uma prática social (a docência de língua estrangeira), partindo de uma situação específica (o contexto de formação inicial). O objetivo é o de refletir sobre suas ações, suas crenças e seus sentimentos, manifestando um caráter ideológico, subjetivo e temporal. A interação é realizada através da simulação de que sua equipe de orientação está consciente da realização dessa aproximação.

Tais constatações fazem-nos deduzir que os diários podem ser vistos como uma tentativa de inserção discursiva (Gee,1999), a fim de manter o contato entre os componentes da prática social docente, em especial entre os participantes dessa proposta de abordagem de ensino-aprendizagem: a investigação-ação educacional, segundo Carr e Kemmis (1986) e Serrano (1990). Essa investigação considera que a reconfiguração das ações é de caráter participativo e que os envolvidos devem-se apropriar dos seus fazeres, como responsáveis pelas transformações, criticamente informadas, dos seus entendimentos, práticas educacionais reflexivas e espaços de atuação.

\section{DELIMITAÇÃO DO CORPUS}


Escolheu-se, aleatoriamente, o fragmento de um diário da acadêmica em formação C. $O$ trecho a analisar passa a ser transcrito abaixo:

\begin{abstract}
Fiquei surpresa, no primeiro momento da aula, pois a aluna disse não conviver com adolescentes e não saber seus comportamentos. No momento, tive que reestruturar meu pensamento, visto que a aula estava montada para alguém com algum conhecimento prévio do comportamento típico juvenil. A solução que encontrei foi perguntar à aluna do tempo em que ela foi adolescente. Assim, realizei com a aluna um longo diálogo intercultural. Creio que a aula transcorreu normalmente e a aluna teve grande aproveitamento, pois ela disse que passou a ter uma maior compreensão não só do comportamento e da linguagem dos adolescentes brasileiros, como também das características de uma publicidade brasileira direcionada a um público específico.
\end{abstract}

\title{
7. ANÁLISE PRELIMINAR DO FRAGMENTO DO CORPUS
}

Ao lermos o fragmento, acompanhamos a verbalização de um momento de confrontação intercultural numa aula de leitura da acadêmica-professora em formação inicial, que havia proposto a leitura de um texto de publicidade provido de elementos da cultura do adolescente brasileiro contemporâneo. Nessa primeira abordagem, levantamos índices diretos e indiretos de seu pensar (crenças e saberes), sentir (sentimentos e valores) e fazer (atitudes e práticas), enquadrando-os na relação complexa docente-aluna, da qual fazem parte (ao menos) o papel desempenhado por C, o contexto da "diferença situada" manifestada na/pela ruptura momentânea do elo cooperativo estabelecido pela aluna, e a representação mental da aluna que $\mathrm{C}$ vinha mantendo. É importante ressaltar que esta análise não tem pretensões de exaustividade, limitando-se a um percurso exploratório.

Primeiramente, notamos que a acadêmica manifesta um sentimento de surpresa diante de uma situação inesperada, pois sua aula estava preparada para alguém que conhecesse o público adolescente (esta era a imagem que $\mathrm{C}$ havia feito de sua aluna para efeito de planejamento de unidade de curso): Fiquei surpresa...pois a aluna disse não conviver com adolescentes e não saber seus comportamentos. Segundo D'Andrade, esse sentimento é ativado no momento em que há um choque entre a perspectiva da acadêmica e o comportamento de sua aluna. Para resolver o impasse, a acadêmica reage (note-se o verbo principal): Tive que reestruturar meu pensamento. Essa atitude revela, segundo Gee (1999), uma configuração identitária entre os papéis assumidos: a acadêmica assume-se professora e reage com o saber-fazer, pois dá uma solução ao problema enfrentado. Temos aqui uma situação dentro do paradigma 
da complexidade de acordo com Morin (1996), uma vez que o contexto sócio-subjetivo (Bronckart,1999) tornou-se complicado envolvendo a aula, a acadêmica e sua aluna hispano-falante.

Ao mesmo tempo, notamos que a acadêmica usa um processo cognitivo de distanciamento crítico para equacionar sua conduta. Seu lado afetivo está calcado na intenção de resolver um problema não esperado. Com isso, ela aciona, em consonância com o modelo mental de D'Andrade (1987), um estado ativo de resolução de problemas. Apesar dessa saída, o lado dos sentimentos e da conduta não estão bem definidos, pois a atitude da acadêmica é sentida como uma injunção, e não como uma decisão, devido à especificidade das circunstâncias. Por outro lado, podemos levantar indícios de uma reconfiguração prática, quando a acadêmica lança hipoteticamente uma alternativa que tenta reinserir a aluna (em termos de faixa etária) no universo textual da leitura: A solução que encontrei foi perguntar à aluna do tempo em que ela foi adolescente. Esse procedimento consistiu na emergência de um saberfazer de superação intercultural (em termos de cultura de faixa-etária) para a situação e o local dos sujeitos envolvidos.

Na perspectiva de Gee (1999), a acadêmica deixa transparecer um comportamento pessoal e cultural que inclui uma crença, pois ela esperava que sua aluna tivesse conhecimento sobre o comportamento dos adolescentes. Ao constatar que esse valor não era compartilhado, tomou uma outra conduta e reagiu com uma estratégia compensatória. Nesse momento fica explícita uma configuração política: a acadêmica assume um poder ao solucionar com responsabilidade algo inesperado. Demonstra, assim, uma firmeza no seu papel enquanto professora que deve solucionar os problemas de sala de aula. Segundo D'Andrade, temos um parâmetro cognitivo do modelo cultural da mente no nível das resoluções.

No penúltimo trecho, encontramos uma asserção: Creio que a aula transcorreu normalmente e a aluna teve grande aproveitamento. Ao usar o verbo no eixo do crer, fica evidente um traço importante da cultura de ensinar da acadêmica que diz acreditar que ensinou e que a aluna aprendeu. É um deslizamento para o modelo tradicional de ensino-aprendizagem: a crença de que o professor - pelo simples exercício da prática docente - ensina e o aluno aprende. Podemos situar essa afirmação em termos da configuração histórico-relacional da interação social, conforme Gee, pois a 
acadêmica faz conexões com o passado histórico da sua forma de ver e sentir o ensino-aprendizagem. Com esse fio de negociação, mantém a interação na situação.

Dessa forma, a acadêmica procura interagir com as idéias e os comportamentos passados e trazê-los para a situação corrente. Há coerência discursiva nesse procedimento, uma vez que sua conduta está firmada na configuração semiótica (Gee, op.cit.), isto é, no nível das regularidades formais, pois, no início do seu diário, o objetivo didático assinalado (que não está expresso no fragmento em questão) era "Pretendo, nessa aula, fazer uma leitura intercultural sobre os comportamentos e valores dos adolescentes. Meu objetivo é mostrar o comportamento e a linguagem juvenil, numa publicidade direcionada ao público adolescente feminino. Para isso, recorri aos fundamentos de...e de ...

Para concluir essa análise preliminar, podemos deduzir que as crenças e os conceitos sobre ensino de leitura em português para estrangeiros referem-se a: leitura como processo cognitivo e leitura como experiência intercultural.

\section{DISCUSSÃO DOS RESULTADOS PRELIMINARES}

Percebemos que a acadêmica-professora teve um lance de consciência sobre a sua posição como professora e teve uma solução para o impasse. Numa reação injuntiva colocou em prática o seu saber-fazer, utilizando um processamento consciente de conceito de ensino de leitura. Dentro de uma perspectiva intercultural de leitura, gerenciou sua prática como professora que já sabe dar soluções para as situações imprevistas. Verificamos a tendência de uma evolução no conceito de ensino de uma língua estrangeira de C. Esse procedimento está contemplando os fundamentos de Fleury (1999) e Morin (1996) sobre o ensino intercultural de línguas e o paradigma da complexidade.

Há também sinais de maturação no conceito de ensino reflexivo de línguas, pois a acadêmica desenvolveu uma cultura de ensinar que está adquirindo com sua experiência em sala de aula de português para estrangeiros. Percebemos que ela utilizou, dentro da psicologia cognitiva de Vygotsky (1993), um indicador de consciência sobre formação de conceitos de leitura, bem como converteu em decisão 
consistente sua crença sobre as possíveis resoluções que uma professora precisa ter em sala de aula a fim de dar uma resposta a seus alunos.

Podemos acompanhar, mais uma vez, a ativação dos parâmetros cognitivos do modelo de D'Andrade (1987) quando ela modificou seus primeiros conceitos de ensino e amadureceu-os, transmitindo representações mentais mais conscientes. Podemos notar um crescimento cognitivo em relação aos conceitos de ensino de leitura da acadêmica no momento em que ela ativa a relação identitária da sua aluna com a época da adolescência. Com essa solução a acadêmica-professora procede a uma horizontalização de superação das hierarquias e das diferenças culturais, pois conseguiu com que sua aluna, que manifestava uma relação de evitação, de exclusão, de aversão à imagem de adolescente, passasse a concordar com a identificação com aspectos pessoais do tempo em que foi adolescente. A acadêmica-professora elicitou, assim, a emergência de uma relação do aluno com o contexto pessoal até antes apagado, propiciando a construção de um metacontexto intercultural de leitura.

Alguns pontos básicos poderiam ser destacados na análise desse fragmento: a acadêmica está passando por um processo de conscientização do ato de ensinar e sua postura condiz com a abordagem da investigação-ação que vem sendo feita durante o percurso da nossa pesquisa.

\section{BIBLIOGRAFIA}

BAKHTIN, Mikhail. Estética da criação verbal. São Paulo: Martins Fontes, 1992. BRONCKART, Jean-Paul. Atividades de linguagem, textos e discursos: por um interacionismo sócio-discursivo. São Paulo: EDUC,1999.

CARR, W.; KEMMIS, S. Becoming critical: educacion, knowledge and action research. Brighton, UK: The Falmer Press, 1986.

D'ANDRADE, Roy. A folk model of the mind. In QUINN, Naomi; HOLLAND, Dorothy. Cultural Models in Language and Thought. Cambridge: Cambridge University Press, 1987.

FLEURY, Reynaldo Matias (org). Intercultura e Movimentos sociais. Florianópolis: MOVER/NUP, 1998.

FLEURY, Reynaldo Matias. Multiculturalismo e interculturalismo nos processos educacionais. Disponível em: www.ced.ufsc.br/nucleos/mover/. Acesso em 28 de agosto de 2003. 
. Educação intercultural e complexidade. Disponível em:

www.ced.ufsc.br/nucleos/mover/. Acesso em 28 de agosto de 2003.

GEE, James $P$. The social mind: language, ideoloy and social practice. New York: Bergin \& Garvey, 1992.

GEE, James P. Social linguistics and literacies. London: The Falmer Press, 1999.

GEE, James P. An introduction to discourse analysis: theory and method. London: Routledge,1999.

GINZBURG, Carlo. 0 queijo e os vermes: o cotidiano e as idéias de um moleiro perseguido pela inquisição. São Paulo: Companhia das Letras, 1998.

KRAMSCH, Claire. Context and Culture in Language Teaching. 3.ed. Oxford: Oxford University Press, 1996.

MORIN, Edgar. O problema epistemológico da complexidade. Portugal:

Publicações Europa América, 1996.

PORLÁN Rafael ; MARTíN José. El diario del profesor. 4.ed. Colección:

Investigación y Enseñanza. Sevilla: Díada Editora S.L.,1997.

REYNALDI, Maria Ângela Abbade Chimelo. Dissertação de mestrado. A cultura de ensinar língua materna e língua estrangeira em um contexto brasileiro. São Paulo. USP. 1999.

SERRANO, Maria Glória Perez. Investigación - acción: aplicaciones al campo social y educativo. Madrid: Dykinson, 1990.

VYGOTSKY, L.S. Pensamento e linguagem. São Paulo: Martins Fontes,1993. 